\title{
Alumina Template-Dependant Growth of Cobalt Nanowire Arrays
}

\author{
L. Malferrari, ${ }^{1}$ A. Jagminiene, ${ }^{2}$ G. P. Veronese, ${ }^{3}$ F. Odorici, ${ }^{1}$ M. Cuffiani, ${ }^{4}$ and A. Jagminas ${ }^{2}$ \\ ${ }^{1}$ Istituto Nazionale di Fisica Nucleare, Sezione di Bologna, Viale B. Pichat 6/2, 40127 Bologna, Italy \\ ${ }^{2}$ Department of Electrochemical Kinetics, Institute of Chemistry, A. Goštauto 9, 01108 Vilnius, Lithuania \\ ${ }^{3}$ Istituto per la Microelettronica ed Microsistemi del CNR, Via Gobetti 101, 40129 Bologna, Italy \\ ${ }^{4}$ Dipartimento di Fisica, Universitá di Bologna, Viale B. Pichat 6/2, 40127 Bologna, Italy
}

Correspondence should be addressed to A. Jagminas, jagmin@ktl.mii.lt

Received 26 September 2008; Accepted 20 March 2009

Recommended by Vladimir M. Shalaev

Different electrochemical regimes and porous alumina were applied for template synthesis of cobalt nanowire ( $n w$ ) arrays, revealing several peculiar cases. In contrast to quite uniform filling of sulfuric acid alumina templates by alternating current deposition, nonuniform growth of the Co $n w$ tufts and mushrooms was obtained for the case of oxalic acid templates. We showed herein for the first time that such configurations arise from the spontaneous growth of cobalt $n w$ groups evolving from the cobalt balls at the Al/alumina interface. Nevertheless, the uniform growth of densely packed cobalt $n w$ arrays, up to tens of micrometers in length, was obtained via long-term direct current galvanostatic deposition at low current density using oxalic acid templates one-side coated by conducting layer. The unique point of this regime is the formation of hexagonal lattice Co $n w s$ with a preferred (100) growth direction.

Copyright () 2009 L. Malferrari et al. This is an open access article distributed under the Creative Commons Attribution License, which permits unrestricted use, distribution, and reproduction in any medium, provided the original work is properly cited.

\section{Introduction}

Cobalt nanowires (nws) and nanoparticles, produced with controllable nanodimensions and spacing, organized into ordered arrays, attract great interest for their enhanced vertical magnetic anisotropy [1], catalytic properties for carbon nanotubes synthesis [2], high specific heating power [3], and thus becoming the promising material for fabrication of magnetic superstructures and $C^{60}$-based devices and for applications in the therapy of tumors.

To date, various mesoporous materials such as nanochannel glasses [4], perforated polycarbonate membranes [5]. anodic oxide films of aluminum [6], carbon nanotubes [7], and organic molecule networks [8] have been employed as templates for the fabrication of arrays of various materials by means of electroless, sol-gel, hydrothermal, solvothermal, chemical vapor, and electrodeposition approaches.

Porous anodic oxide films of high-purity aluminum are likely the most widely applied templates for preparation of highly ordered $n w$ and nanotube arrays of metals [911 ], semiconductors [12-15], and conducting polymers [16] with well-defined product dimensions at packing density of $10^{9}-10^{11}$ species $/ \mathrm{cm}^{2}$. It is generally accepted that the diameter and density of tube-shaped pores, arranged in the central part of alumina hexagonal cells, can be simply controlled by varying the anodizing voltage of aluminum, while the length of pores, by anodizing time, adjusts some tens of micrometers. There is always a high-resistance barrier layer between the bottom of the alumina pores and aluminum, whose thickness is proportional to the anodizing voltage (usually in the range $1.0-1.2 \mathrm{~nm} / \mathrm{V}$ ) [17, 18]. This barrier layer prevents continuous supply of electrons to the bottom of pores, restricting the effectiveness of electrochemical methods for uniform synthesis of $n w$ arrays. To remove this thin layer or perforate it, at the bottom of alumina nanochannels, various etching solutions [19-21] and different methods [22] have been applied during the last decade. These procedures usually require the detachment of the alumina film from the aluminum substrate, which can be applied only to "thick" alumina templates. Furthermore, the thermal sputtering of gold [23, 24], silver [25], or platinum [26] layer onto the back-side of perforated template as a conducting and well-adhesive layer is crucial once one aims at filling the alumina nanochannels by direct current $(D C)$ deposition.

On the other hand, there always exists the possibility of filling alumina pores by alternating current $(A C)$ regimes, 
leaving intact the barrier layer at the bottom of the pores. According to some opinions [27], AC electrolysis is an ideal method for deposition of metal and semiconductor $n w s$, starting from the bottom of pores. However, different groups using this method $[28,29]$ have recently observed interrupted growth of various polycrystalline materials and just partial depositions, namely, only in a fraction of pores. In our work, we found that the growth of cobalt nws depends much stronger on conditions for fabricating the alumina template than other metals like copper, silver, or tin. For example, only sulfuric acid alumina templates can be successfully filled by Co $n w s$ using $A C$, while the use of the same deposition solution for uniform growth of Co nws in oxalic or phosphoric acid alumina pores is problematic. However, the effects of the template-dependant metal $n w s$ growth by electrodeposition are not pronounced. Therefore, in this study we focus on the investigation of the peculiarities of the Co nws electrochemical growth using oxalic and sulfuric acid alumina templates at different regimes.

Three approaches for cobalt $n w s$ synthesis within the alumina pores were studied and discussed herein:

(i) $A C$ deposition in the as-grown templates,

(ii) $A C$ and $D C$ deposition through a reconstructed barrier layer,

(iii) $D C$ galvanostatic deposition after perforation or detachment of the barrier layer and subsequent evaporation of a metallic layer as a conductive pad.

\section{Experimental}

2.1. Preparation of Alumina Templates. Experiments were carried out using 99.685 at \% (Russia) and 99.99 at \% purity (Goodfellow Ltd.) aluminum foils, from which specimens of dimensions $50 \times 50$ and $15 \times 15 \mathrm{~mm}^{2}$ were, respectively, cut. The surface of specimens was chemically cleaned in the usual manner. The anodization of specimens was carried out using aqueous solution of sulfuric acid (either $1.5 \mathrm{M}$; $18 \pm 0.01^{\circ} \mathrm{C} ; 15 \mathrm{~V}$ or $0.5 \mathrm{M} ; 3 \pm 0.01^{\circ} \mathrm{C} ; 25 \mathrm{~V}$ ) or oxalic acid $\left(0.3 \mathrm{M}, 17 \pm 0.01^{\circ} \mathrm{C} ; 40 \mathrm{~V}\right)$ for a period of $0.5-5.0$ hours, with a vigorous stirring. Two lead sheets and graphite stripes were used as cathodes in sulfuric and oxalic acid anodizing baths, respectively. Under these conditions ordered alumina templates 3.5 to $50 \mu \mathrm{m}$ thick, were obtained. In sulfuric acid, at 15 and $25 \mathrm{~V}$ of anodizing voltage, the average pore diameters $\left(\varnothing_{\text {pore }}\right)$ were $15 \mathrm{~nm}$ and $28 \mathrm{~nm}$ with pitch spacing of 43 and $65 \mathrm{~nm}$, respectively. In oxalic acid a $\varnothing_{\text {pore }}$ of $40 \mathrm{~nm}$ with $108 \mathrm{~nm}$ pitch spacing was obtained.

In order to improve $A C$ and $D C$ deposition, reconstructed (modified) barrier layers were obtained. In particular, $A C$ deposition improves using a thinner layer, while $D C$ deposition is possible only through a perforated barrier layer. Such reconstructed barrier layers were obtained by using both electrochemical and chemical methods. In the electrochemical posttreatment, the anodizing voltage was decreased at the end of anodization process, through a stepwise procedure from 3 to $0.5 \mathrm{~V} / \mathrm{min}$ until the final voltage ranges from 15.0 to $5.0 \mathrm{~V}$. To widen the pores as well as to

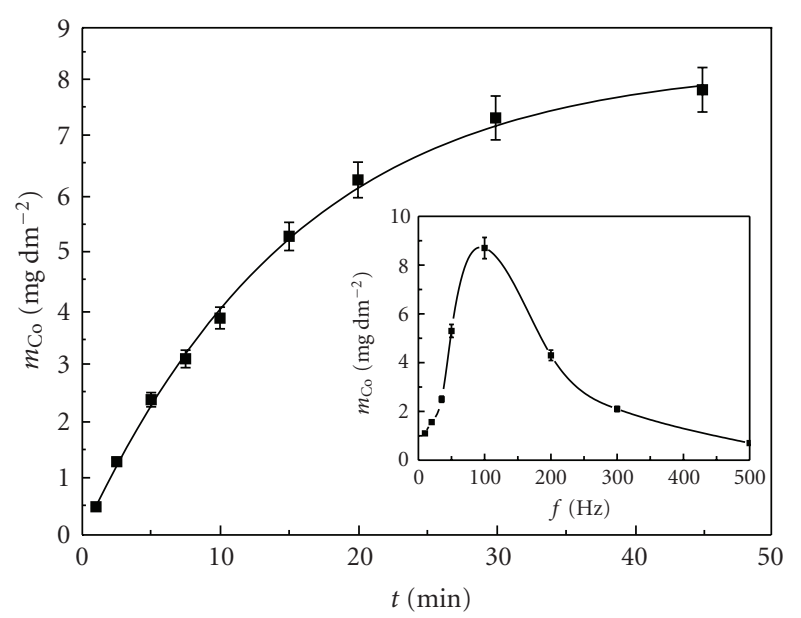

Figure 1: Variation of the amount of Co $\left(m_{\mathrm{Co}}\right)$ inside the alumina pores for the deposition solution made of $0.2 \cos \mathrm{O}_{4}, 0.7 \mathrm{H}_{3} \mathrm{BO}_{3}$, $0.01 \mathrm{M} \mathrm{MgSO}_{4}$, and TEA up to $\mathrm{pH} 5.7$, at constant $A C$ voltage $U_{p-p}$ of $32 \mathrm{~V}, 50 \mathrm{~Hz}$ and $20^{\circ} \mathrm{C}$, as a function of the deposition time. $\varnothing_{\text {pore }}$ $15 \mathrm{~nm}$; template thickness $\left(h_{\mathrm{AAO}}\right) 15 \mu \mathrm{m}$. In the inset, variation of $m_{\text {Co }}$ versus $A C$ frequency $(f)$ for the same deposition solution and $U_{p-p}$ value for 15 minutes of deposition.

dissolve the barrier layer, a solution of either $0.5 \mathrm{M} \mathrm{H}_{3} \mathrm{PO}_{4}$ or $2 \mathrm{M} \mathrm{H}_{2} \mathrm{SO}_{4}$ both kept at $30^{\circ} \mathrm{C}$ for up to 45 minutes time $\left(\tau_{w}\right)$ was applied. To detach the alumina template from the substrate, one-side etching procedures of the electrode window first in $\mathrm{NaOH}$ and then in $0.1 \mathrm{M} \mathrm{CuCl}_{2}+10 \% \mathrm{HCl}$ were used.

The conductive layer on the back side of perforated alumina templates was obtained by evaporating a $100 \mathrm{~nm}$ thick $\mathrm{Cr}$ layer followed by a $150 \mathrm{~nm}$ thick Au layer, using an Edwards E306A thermal evaporator, with a source-to-sample distance of $20 \mathrm{~cm}$.

\subsection{Electrochemistry of the Metal Array Fabrication. For} growing cobalt nws into alumina nanochannels, a solution, composed of $\cos \mathrm{O}_{4}, \mathrm{H}_{3} \mathrm{BO}_{3}, \mathrm{MgSO}_{4}, \mathrm{H}_{2} \mathrm{SO}_{4}$, and triethanolamine, $\mathrm{N}\left(\mathrm{C}_{2} \mathrm{H}_{4} \mathrm{OH}\right)_{3}$ (TEA), was optimized. Analytical grade salts used for preparation of solutions were purchased from Aldrich. All solutions were prepared using Milli-Q water and high purity acids. Co nws inside the alumina pores were grown in thermostated electrochemical cells configured for two or three electrodes for $A C$ and $D C$ electrolysis, respectively. A graphite stripe was used throughout all deposition experiments as a counter electrode, and a silver/silver chloride electrode connected to the cell through the salt/agar-agar bridge was used as a reference. Electrodepositions of cobalt $n w s$ within the alumina pores by $D C$ electrolysis were conducted via potentiostatic and galvanostatic mode for up to 300 minutes. The electrochemical apparatus included a programmable potentiostat/galvanostat PI-50-I. Furthermore, to investigate effects on the Co $n w s$ growth for a maximum 1.5 hour, a function generator (FLUKE PM5138A) was used to supply $A C$ sine wave voltage within the frequency range of $10-$ $1000 \mathrm{~Hz}$ at a fixed peak to peak voltage and a cryostatic 


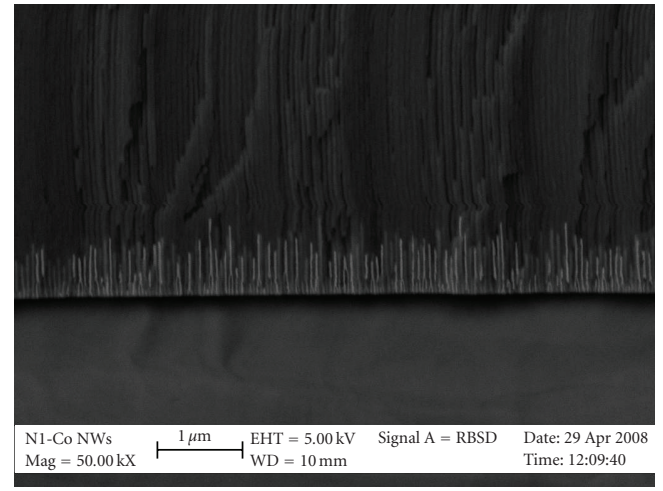

(a)

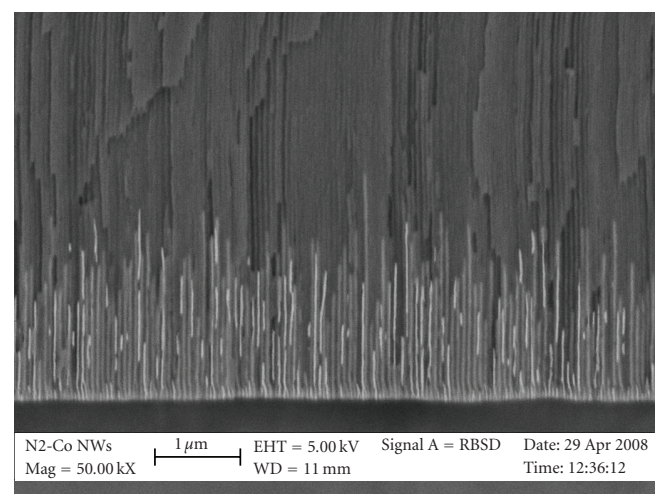

(b)

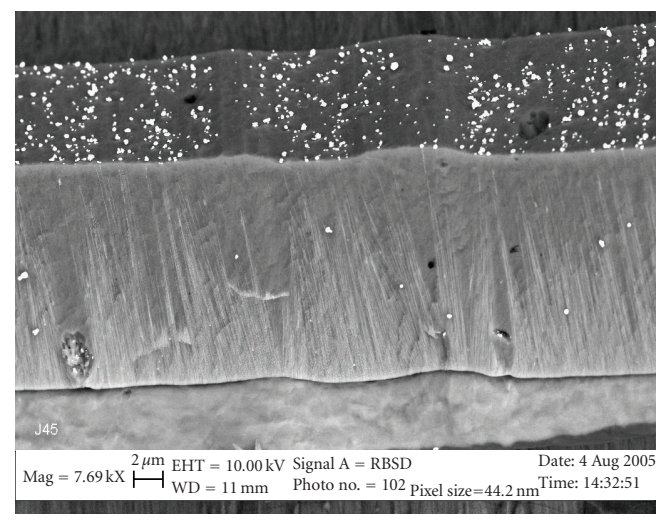

(c)

FIgURE 2: Cross-sectional FESEM images of sulfuric acid alumina templates grown at $(\mathrm{a}, \mathrm{b}) 25$ and (c) $15 \mathrm{~V}$ following the template etching in $2 \mathrm{M} \mathrm{H}_{2} \mathrm{SO}_{4}$ for 15 minutes and deposition of cobalt $n w$ arrays by $A C(50 \mathrm{~Hz})$ treatment in a same as in Figure 1 solution at constant $A C$ current density of $0.3 \mathrm{~A} \mathrm{dm}^{-2}$ and room temperature for: (a) 5, (b) 15 and (c) 60 minutes. (a, b) $h_{\mathrm{AAO}} 18 \mu \mathrm{m}, \varnothing_{\text {pore }} \sim 28$ and $(\mathrm{c}) \sim 20 \mathrm{~nm}$.

system to keep constant the bath temperature fixed in the range of $5-50^{\circ} \mathrm{C}$. Again, for depositions at $A C$ frequency of $50 \mathrm{~Hz}$ under constant effective current density $\left(j_{a c}\right)$ control in the range $0.2-0.65 \mathrm{~A} \mathrm{dm}^{-2}$, a custom made generator was used.

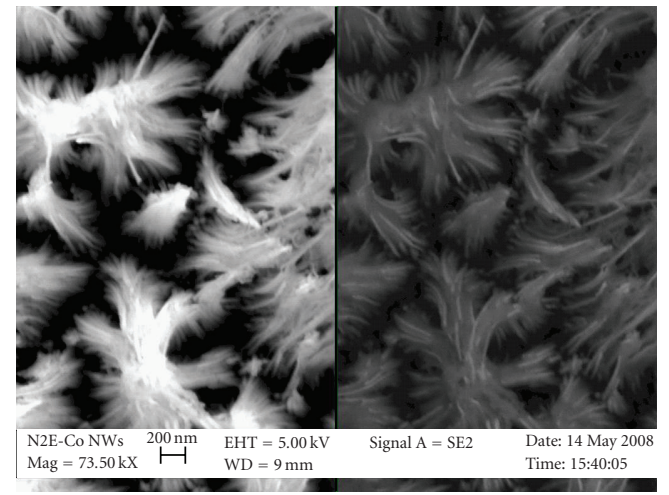

(a)

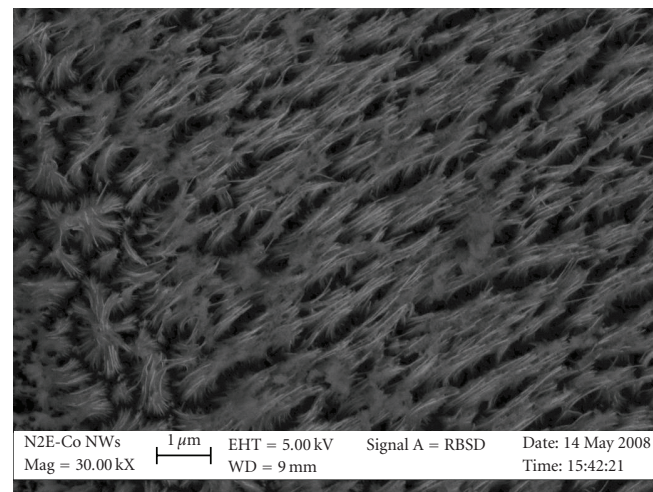

(b)

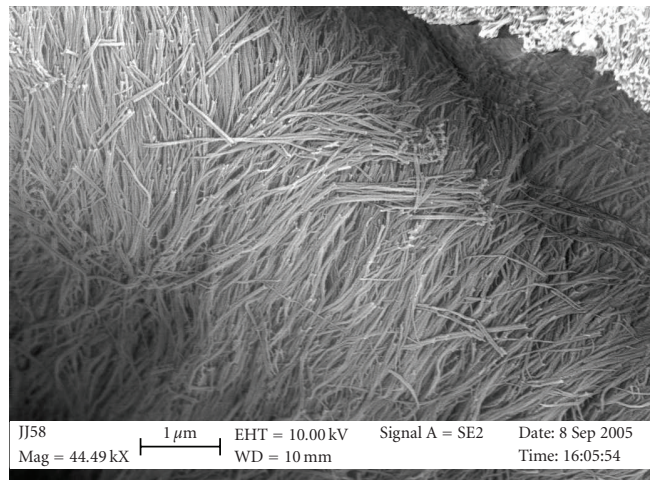

(c)

Figure 3: Top view FESEM images for fragments of Co $n w$ arrays fabricated under the optimized $A C$ deposition conditions in the sulfuric acid alumina template pores after the template etching in $0.5 \mathrm{M} \mathrm{H}_{3} \mathrm{PO}_{4}$ for (a) 30, (b) 70 and (c) 100 minutes.

2.3. Characterization. Nanostructured products deposited within the alumina pores were characterized using a scanning electron microscope (SEM, Philips $30 \mathrm{~L}$ ) and a field emission scanning electron (FESEM, LEO 1530, equipped with an Oxford Instruments INCAPentaFET-X3 EDS detector) microscopes under typical working conditions. For freestanding metal array fabrication, the template was partially or fully dissolved by dipping into $0.5 \mathrm{M} \mathrm{NaOH}$ solution, from 5 to 40 minutes, then carefully rinsed, soaked in deionized 


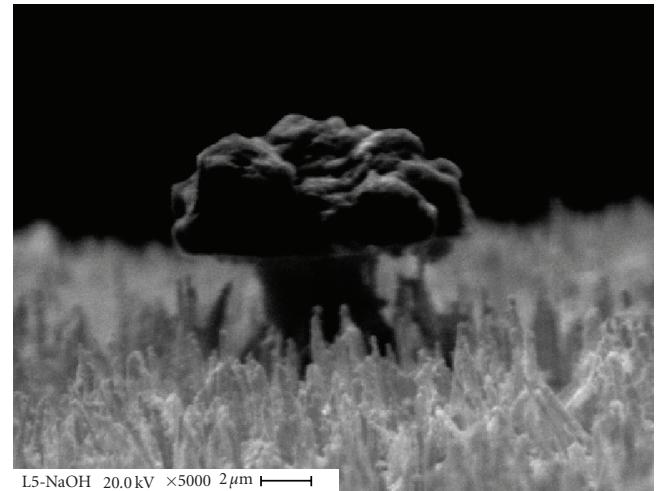

Figure 4: Typical top view SEM images of Co "mushroom" grown by $A C$ treatment of oxalic acid alumina template in the solution of this study. Before deposition the thickness of alumina barrier layer was reduced by lowering the anodizing voltage $\left(U_{a}\right)$ down to final value $\left(U_{a, \text { fin }}\right)$ equal to $15 \mathrm{~V}$.

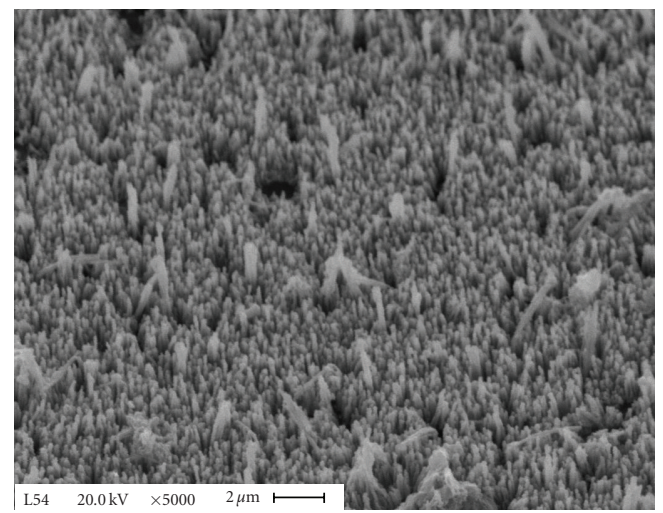

(a)

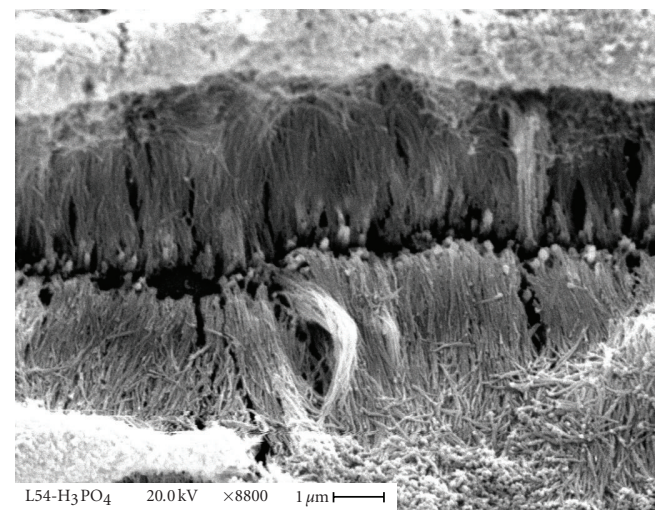

(b)

FIgURE 5: Top view FESEM image for fragments of Co $n w$ arrays fabricated in the oxalic acid alumina pores by $A C(50 \mathrm{~Hz})$ deposition from the optimized solution at $j_{\mathrm{ac}} \sim 0.5 \mathrm{~A} \mathrm{dm}^{-2}$ ( $U_{p-p}$ from 18 to $32 \mathrm{~V}$ ) and room temperature for (a) 10 and (b) 20 minutes. Before depositions, the barrier layer of the as-grown templates was thinned by decreasing anodizing voltage down to $20 \mathrm{~V}$ and etching in $0.5 \mathrm{M}$ $\mathrm{H}_{3} \mathrm{PO}_{4}$ at $30^{\circ} \mathrm{C}$ for 32 minutes. Following depositions the template was etched in the same $0.5 \mathrm{M} \mathrm{H}_{3} \mathrm{PO}_{4}$ solution. water for 10 minutes, neutralized in a solution of $1 \%$ citric acid, rinsed again, and finally dried in a desiccator.

X-ray diffraction analysis was carried out by means of a PANalytical X'Pert PRO powder diffractometer equipped with an XCelerator detector for $\mathrm{CuK}_{\alpha}$ radiation $(40 \mathrm{~mA}$, $40 \mathrm{kV})$. Diffraction patterns were acquired at $2 \Theta$ steps of $0.05^{\circ}$ and $80 \mathrm{~s} /$ step exposure.

2.4. Analysis. Before analyzing the deposited cobalt, in order to remove the residual ions entrapped in the alumina template, the specimens were thoroughly rinsed and soaked in deionized water for about 10 minutes. The amount of cobalt was determined after the complete dissolution of $\mathrm{Co}^{0}$ nanowires from $8.0 \mathrm{~cm}^{2}$ template surface in a mixture of hydrogen peroxide (25\%) and nitric acid (1 : $8 \mathrm{v} / \mathrm{v})$. All solutions used for nanowires dissolution, sample rinsing, and further double soaking in deionized water for 10 minutes were collected together, diluted to constant volume up to $100 \mathrm{~mL}$, and analyzed quantitatively using a computercontroled Perkin Elmer Lambda 35 UV/Vis spectrophotometer. To increase absorbance detection sensitivity of cobalt analyte at $520 \mathrm{~nm}$, Nitroso-R-salt solution was used as a complexing agent. Reproducibility of the analysis was checked with 3 repeated experiments. Standard solutions were made from 99.999 at \% grade cobalt. A linear BeerLambert law calibration curve of cobalt absorbance versus ppm was obtained using a series of standard concentrations between 3 and 60 . The concentration of unknown cobalt was calculated using a typical calibration graph.

\section{Results and Discussion}

3.1. The Composition of the Deposition Solution. One parameters we were able to easily control is the composition of deposition electrolyte. In this study, the composition of solution for Co nws electrosynthesis within the alumina pores was organized using $\cos \mathrm{O}_{4}$, as a precursor for cobalt ions and $\mathrm{H}_{3} \mathrm{BO}_{3}$, as a buffering ingredient to prevent any $\mathrm{pH}$ variation within the alumina pores and to inhibit the formation of cobalt hydroxide species as a result of hydrogen evolution [30]. Furthermore, $\mathrm{MgSO}_{4}$ was added as $\mathrm{Mg}^{2+}$ source to prevent the breakdown of alumina barrier layer [31] during $A C$ depositions. To adjust the $\mathrm{pH}$ of solutions, $\mathrm{H}_{2} \mathrm{SO}_{4}$ and triethanolamine (TEA) $1: 1$ solutions in water were used. From a review of patent's literature [32], it arises that these components have been frequently used for $A C$ coloring of anodized aluminum in the $\mathrm{Co}^{2+}$-containing baths. To optimize the concentration of components and the solution $\mathrm{pH}, 15 \mu \mathrm{m}$ thick sulfuric acid alumina templates were used. All depositions in this setup were performed using $50 \mathrm{~cm}^{2}$ specimens, a $50 \mathrm{~Hz}$ frequency $A C$ and constant peak-to-peak voltage of $32 \mathrm{~V}$, for 15 minutes. Observation of the alumina color uniformity and the amount of deposited cobalt were the main criteria adopted in the search of the optimal composition. Consequently, the solution composed of $0.2-0.25 \mathrm{M} \cos \mathrm{O}_{4}, 0.65-0.7 \mathrm{M} \mathrm{H} \mathrm{H}_{3} \mathrm{BO}_{3}, 0.005-0.05 \mathrm{M}$ $\mathrm{MgSO}_{4}$ and TEA, to adjust a $\mathrm{pH}$ at 5.5-5.75, was determined as optimum for $A C$ filling of alumina templates with Co $n w s$, 


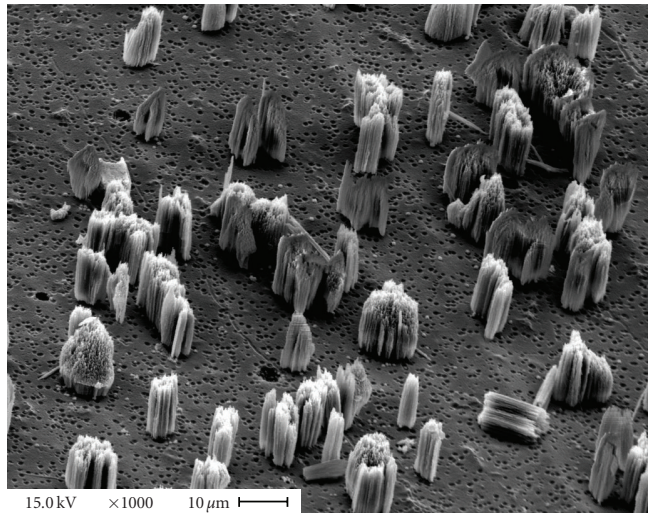

(a)

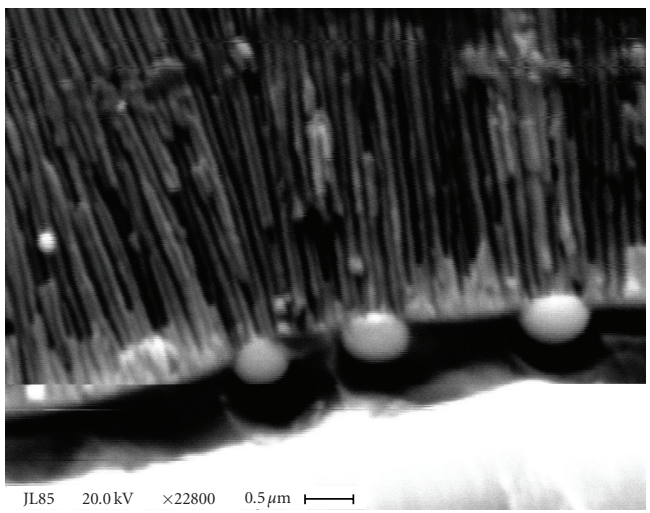

(c)

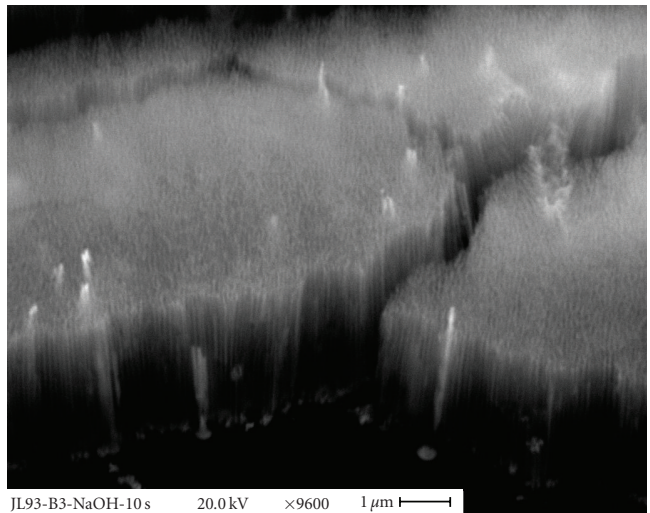

(b)

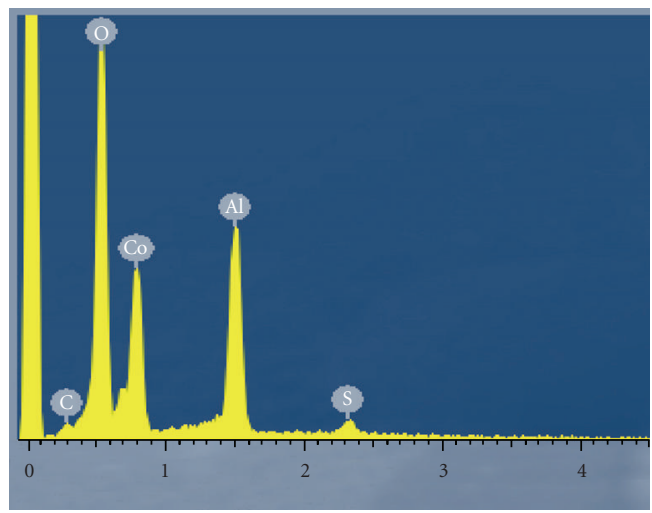

(d)

FIGURE 6: SEM images of reconstructed oxalic acid alumina templates after deposition of Co nws by $A C$ treatment in the solution as in Figure 1 at $U_{p-p} 32 \mathrm{~V}$ and room temperature for 20 minutes. $h_{\mathrm{AAO}} 13 \mu \mathrm{m}, \varnothing_{\text {pore }} \sim 45 \mathrm{~nm}, \tau_{w} 30$ minutes in $0.5 \mathrm{M} \mathrm{H}_{3} \mathrm{PO}_{4}$. (a) top-side view after dissolution some part of alumina; (b) in plane view; (c) cross-sectional view. (d) EDX spectrum of specimen.

having average $\varnothing_{\text {pore }}$ of $15 \mathrm{~nm}$. The XRD patterns (not shown herein) of Co $n w s$ deposited from this solution demonstrated the polycrystalline nature of cobalt in hexagonal closely packed lattice. For any of the used $A C$ deposition conditions, no phase modification in the XRD patterns was observed.

3.2. AC Deposition into As-Grown Templates. Figure 1 demonstrates typical variation of the amount of Co assembled inside the alumina pores $\left(m_{\mathrm{Co}}\right)$ with the deposition time and $A C$ current frequency $(f)$ used for depositions. As seen, the amount of deposited Co increases linearly during the first 10-20 minutes of $A C$ treatment at constant voltage. However, with further processing the rate of deposition inside the alumina pores progressively decreases. Moreover, it was observed that this solution allows the growth of cobalt $n w s$ within a wide range of $A C$ frequencies, ca. from 10 to $200 \mathrm{~Hz}$, coloring the template uniformly from bronze to deep black. A further increase in frequency, up to $1000 \mathrm{~Hz}$, results in a smaller amount of deposited cobalt and therefore in a lighter template color intensity. As seen from the inset of Figure 1, the maximum amount of cobalt can be deposited using $100 \mathrm{~Hz}$ frequency. The bath temperature within 10 to $40^{\circ} \mathrm{C}$ range was found to have negligible effect on the amount of deposited cobalt as well as on the uniformity of depositions.

In order to visualize the uniformity of Co $n w s$ growth by $A C$ deposition, cross-sections of the alumina templates were investigated using field emission scanning electron microscopy (FESEM). Figures 2(a)-2(c) show the arrangement of Co $n w s$ deposited inside the pores of sulfuric acid alumina templates at the same $A C$ frequency $(50 \mathrm{~Hz})$ and peak-to-peak voltage $\left(U_{p-p}\right)$ during 5,15 , and 60 minutes, respectively. The obtained data show quite uniform growth of Co nws from the bottom of almost all pores only at the onset of the process. The pores filling rate depends on $A C$ voltage and of the pores diameter $\emptyset_{\text {pore. }}$ In case of sulfuric acid alumina templates formed at $25 \mathrm{~V}\left(\varnothing_{\text {pore }} 25-\right.$ $30 \mathrm{~nm}$ after pore widening), the uniform growth corresponds to a filling rate $v_{C o} \sim 6 \mu \mathrm{m} / \mathrm{h}$ for the first 10 minutes of deposition at a constant $U_{p-p}$ of $32 \mathrm{~V}$. Processing further, $v_{C o}$ decreases due to an increase in the template resistance, causing a reduced $A C$ current. A smaller $\varnothing_{\text {pore }}$ results in a faster growth of cobalt $n w s$ under the same $A C$ treatment conditions. For example, $v_{C o} \sim 9.3 \mu \mathrm{m} / \mathrm{h}$ was detected at $U_{p-p}$ of $32 \mathrm{~V}$ for alumina templates with average $\varnothing_{\text {pore }}$ of $15 \mathrm{~nm}$. It can be observed from Figure 2(b) that some cobalt $n w s$ grew faster than $n w s$ front. For prolonged $A C$ treatment, 


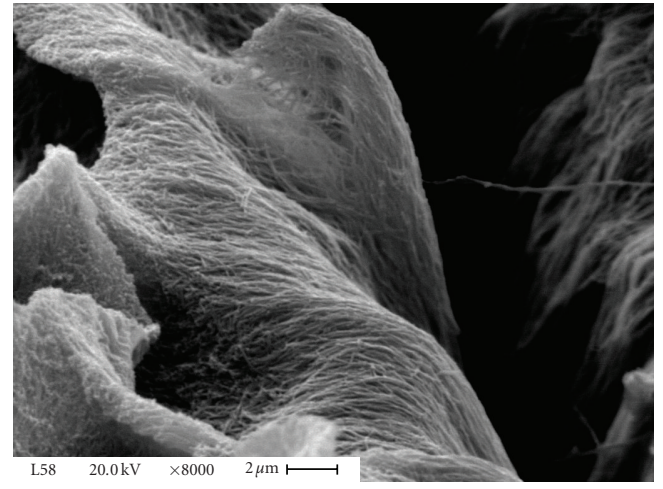

(a)

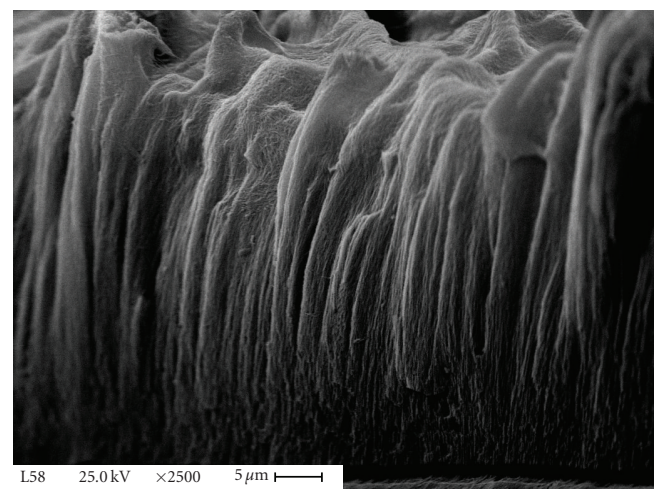

(b)

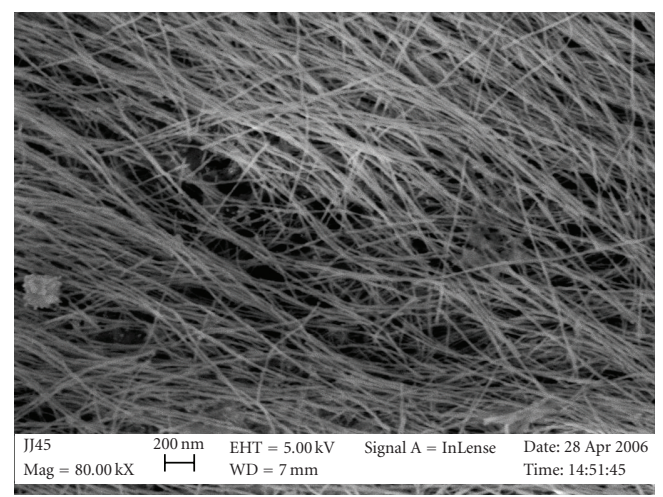

(c)

FIgURe 7: Top view SEM images of Co $n w$ arrays after dissolution of oxalic acid alumina template $(a, b)$ in part and (c) fully. Template fabrication: anodizing 3 hours; $U_{a \text {,fin }} 5.0 \mathrm{~V} ; \tau_{w} 30$ minutes in $0.5 \mathrm{M}$ $\mathrm{H}_{3} \mathrm{PO}_{4}$. Following the detachment of alumina from the substrate and a back-side evaporation of a $\mathrm{Cr} / \mathrm{Au}$ layer, the deposition of $\mathrm{Co}$ was conducted in the solution: $0.45 \cos \mathrm{O}_{4}, 0.7 \mathrm{M} \mathrm{H}_{3} \mathrm{BO}_{3}$, and TEA up to $\mathrm{pH} 5.7$ at a constant $D C$ current density of $0.12 \mathrm{~mA} \mathrm{~cm}^{-2}$ for 5 hours.

this progressively leads to the formation of more and more uneven lengths of Co nws emerging onto the template surface in cobalt caps (see Figure 2(c)). We suggest that at least two reasons can be linked with the retarded growth of Co nws: (i) gas burbles formation resulting in the plug of some pores

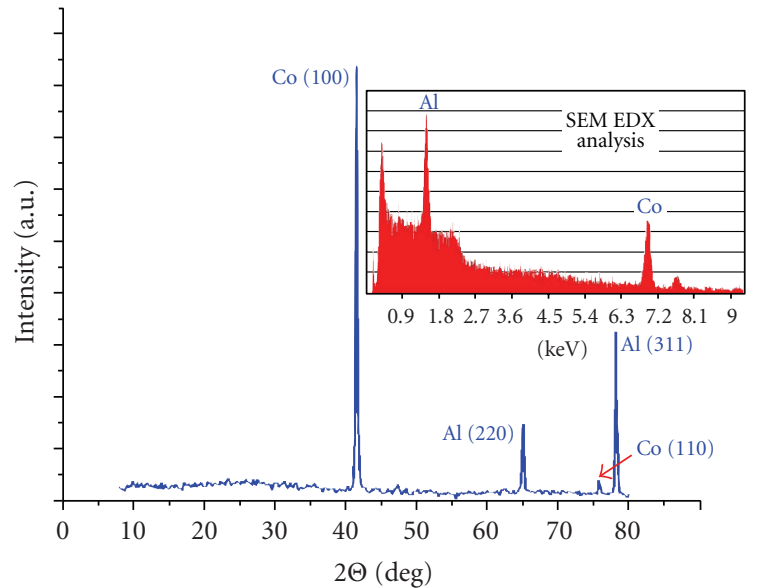

FIgURE 8: Typical X-ray diffraction spectrum for a Co $n w s$ array fabricated inside the oxalic acid alumina pores by $D C$ deposition under the same galvanostatic conditions as in Figure 6.

and nonuniform current density from pore-to-pore due to nonuniform resistance of alumina barrier layer.

The nws height uniformity was found to be independent on the $f$.

Typical morphology of cobalt $n w$ arrays assembled inside the sulfuric acid alumina pores by short-term $A C$ deposition after the template etching is presented in Figure 3. As seen, in cases of 1-2 $\mu \mathrm{m}$ length of Co $n w s$ they are densely packed and quite uniform in length.

\subsection{AC and DC Deposition through a Reconstructed Barrier} Layer. The key feature of $A C$ deposition process of the densely packed Co $n w s$ is that only sulfuric acid alumina templates can be successfully applied. Fabrication of Co $n w s$ in the nanochannels of alumina template formed in the oxalic or phosphoric acid anodizing baths, however, is problematic for $A C$ deposition. One possible explanation for this effect is the adsorption and incorporation of acid anions at some depth of the alumina barrier layer, changing the state of alumina/solution interface at the bottom of pores (surface charge, free energy, etc.) and preventing the discharge of $\mathrm{Co}^{2+}$ ions. Besides, highly ordered oxalic and phosphoric acid alumina templates are usually formed at higher voltages $[6,33,34]$ and, therefore, present much thicker barrier layers at the metal/oxide interface. To use these templates for $A C$ deposition of various materials, the step-wise voltage decreasing at the end of anodizing process has been proposed [17] and successfully used in several works. We found herein that this is helpful also for the Co case, however, only for short-time processing. The Co nws array produced by long $A C$ treatment, that is, longer than 15 minutes, viewed in the template cross-sections after the dissolution of some part of template, clearly show nonuniform growth from pore to pore and the formation of mushroomed Co fragments (Figure 4) outgrowing from the breakdown sites of the alumina barrier layer. The modification of alumina barrier layers through (i) the decreasing of anodizing voltage $\left(U_{a}\right)$ at the end of oxalic acid alumina growth down within 13 to $5 \mathrm{~V}$, (ii) the 
cathodic treatment in the same anodizing bath for 3 minutes at various potentials, and (iii) the chemical etching in the solution of sulfuric acids inhibits the uniformity of the depositions (see Figure 5). The most uniform alumina color was obtained after decreasing $U_{a}$ and chemical etching in the solution of sulfuric acid. Nevertheless, in this case the SEM cross-sectional observations of templates revealed the formation of Co nws tufts in random areas of template (Figure 6(a)). It is worth to note that these tufts were found to arise from cobalt balls (Figures 5(b), 6(b)-6(d)) formed at the metal/template interface. It is clear that the formation of metallic Co balls started below the pores in places where the barrier layer damage takes place. Therefore, the current strength in such places ought to increase drastically. So, we suggest that under these conditions except the spontaneous Co $n w$ bundles growth, the electrochemical etching of aluminium and the formation of Co balls proceed.

Time and potential variables in the cathodic pretreatment of the oxalic acid templates in the anodizing bath as well as variations of the deposition potential were found to be ineffective for uniform, rod-like Co formation by $A C$ deposition through the remained barrier layer. Note that in case of $D C$ depositions through the remained barrier layer at constant potential, the detachment of alumina template from the substrate proceeds just after several minutes of such treatment independently on the value of potential applied.

3.4. Galvanostatic Deposition. An alternative approach for Co $n w s$ deposition was examined for oxalic acid alumina templates by $D C$ galvanostatic deposition, after removing or opening the barrier layer on the pores bottom. In this setup, we used either an electrochemical/chemical method for the barrier layer perforation, or we detached the alumina from the substrate, removed the barrier layer, and made a subsequent evaporation of $\mathrm{Cr} / \mathrm{Au}$ layer, acting as a conducting pad. The resulting Co $n w s$ released from the asfilled templates are shown in images $7(\mathrm{a}), 7(\mathrm{~b})$, and $7(\mathrm{c})$ of Figure 7. We found here that by applying a low current density during the entire deposition process, ca. $\leq 0.2 \mathrm{~mA}$ $\mathrm{cm}^{-2}$, well-ordered, densely packed, continuous, and highly aligned Co $n w$ arrays, faithfully reproducing the shape of the pores and with height up to several tens of micrometers, can be synthesized by this way. Furthermore, after alumina dissolution these $n w s$ seem not to collapse and stuck together, as in the case of $A C$ synthesis, implying an easier application in future nanoelectronics and novel efficient sensors.

A typical XRD profile of a template filled with Co $n w s$ via $D C$ galvanostatic deposition at $0.12 \mathrm{~mA} \mathrm{~cm}^{-2}$ for 5 hours is shown in Figure 8. Only a single peak is observable at $2 \Theta$ $=41.59$. According to the XRD library patterns for bulk Co (PDF 89-4308), this peak corresponds to the (100) reflection of the hexagonal closely packed Co lattice. Further, some additional weak signals situated at $2 \Theta=47.39$ and $2 \Theta=$ 75.89, ascribed to hexagonal Co phase in (101) and (110) directions, respectively, can be observed. These weak features inferred that Co nws are not single crystals but consist of oriented polycrystals with a preferred (100) growth direction perpendicular to the substrate. We note that the preferential growth of hexagonal Co phase in (100) direction is not a trivial case and differs from the growth of Co nws inside the alumina pores via $A C$ and potentiostatic depositions reported recently in [35], where the formation of Co $n w$ arrays with (110) orientation has been demonstrated.

\section{Conclusions}

In the present work, we show how different types of processing conditions influence the quality and phase composition of Co nws deposited inside the sulphuric and oxalic acid alumina templates. In this context, a suitable method for the fabrication of densely packed, perfectly aligned Co $n w s$, with high aspect ratio, within the oxalic acid alumina pores, was found. Moreover, we showed that Co nws deposited inside the alumina pores under $D C$ galvanostatic mode consist of oriented polycrystals of hexagonal cobalt with a preferred (100) growth direction, that is not trivial case. The synthesis procedure described above allows a long-term $D C$ galvanostatic deposition, at low current density in optimized $\mathrm{Co}^{2+}$-containing solution, and is based on the formation of template by $\mathrm{Al}$ anodizing, reanodizing at decreased voltage, detachment from the substrate, chemical etching for the perforation of alumina barrier layer at the bottom of pores and a one-side evaporation of a $\mathrm{Cr} / \mathrm{Au}$ layer for ohmic contact. Important issues such as growth rate, phase composition, uniformity and continuity of encapsulated Co $n w s$ as a function of applied deposition methods have been also presented.

\section{Acknowledgments}

This research was partially supported by the grants from the Lithuanian State Science and Studies Foundation T-11608 and C-07035, and partially by the italian Istituto Nazionale di Fisica Nucleare for the NANOCHANT2 experiment of the commission 5 .

\section{References}

[1] R. Ferré, K. Ounadjela, J. M. George, L. Piraux, and S. Dubois, "Magnetization processes in nickel and cobalt electrodeposited nanowires," Physical Review B, vol. 56, no. 21, pp. 14066-14075, 1997.

[2] V. Ivanov, J. B. Nagy, Ph. Lambin, et al., "The study of carbon nanotubules produced by catalytic method," Chemical Physics Letters, vol. 223, no. 4, pp. 329-335, 1994.

[3] M. Zeisberger, S. Dutz, R. Müller, R. Hergt, N. Matoussevitch, and H. Bönnemann, "Metallic cobalt nanoparticles for heating applications," Journal of Magnetism and Magnetic Materials, vol. 311, no. 1, pp. 224-227, 2007.

[4] Y.-J. Han, J. M. Kim, and G. D. Stucky, "Preparation of noble metal nanowires using hexagonal mesoporous silica SBA-15," Chemistry of Materials, vol. 12, no. 8, pp. 2068-2069, 2000.

[5] J. K. N. Mbindyo, T. E. Mallouk, J. B. Mattzela, et al., "Template synthesis of metal nanowires containing monolayer molecular junctions," Journal of the American Chemical Society, vol. 124, no. 15, pp. 4020-4026, 2002.

[6] H. Masuda and K. Fukuda, "Ordered metal nanohole arrays made by a two-step replication of honeycomb structures of 
anodic alumina," Science, vol. 268, no. 5216, pp. 1466-1468, 1995.

[7] P. M. Ajayan, O. Stephan, Ph. Redlich, and C. Colliex, "Carbon nanotubes as removable templates for metal oxide nanocomposites and nanostructures," Nature, vol. 375, no. 6532, pp. 564-567, 1995.

[8] T. Hassenkam, K. Nørgaard, L. Iversen, C. J. Kiely, M. Brust, and T. Bjørnholm, "Fabrication of 2D gold nanowires by self-assembly of gold nanoparticles on water surfaces in the presence of surfactants," Advanced Materials, vol. 14, no. 16, pp. 1126-1130, 2002.

[9] J.-S. Yu, J. Y. Kim, S. Lee, J. K. N. Mbindyo, B. R. Martin, and T. E. Mallouk, "Template synthesis of polymer-insulated colloidal gold nanowires with reactive ends," Chemical Communications, no. 24, pp. 2445-2446, 2000.

[10] Z. Zhang, S. Dai, D. A. Blom, and J. Shen, "Synthesis of ordered metallic nanowires inside ordered mesoporous materials through electroless deposition," Chemistry of Materials, vol. 14, no. 3, pp. 965-968, 2002.

[11] Z. Zhang, D. Gekhtman, M. S. Dresselhaus, and J. Y. Ying, "Processing and characterization of single-crystalline ultrafine bismuth nanowires," Chemistry of Materials, vol. 11, no. 7, pp. 1659-1665, 1999.

[12] R. V. Parthasarathy, K. L. N. Phani, and C. R. Martin, “Template synthesis of graphitic nanotubules," Advanced Materials, vol. 7, no. 11, pp. 896-897, 1995.

[13] S. M. Liu, L. M. Gan, L. H. Liu, W. D. Zhang, and H. C. Zeng, "Synthesis of single-crystalline $\mathrm{TiO}_{2}$ nanotubes," Chemistry of Materials, vol. 14, no. 3, pp. 1391-1397, 2002.

[14] A. Jagminas, R. Juškènas, I. Gailiūtè, G. Statkute, and R. Tomašiūnas, "Electrochemical synthesis and optical characterization of copper selenide nanowire arrays within the alumina pores," Journal of Crystal Growth, vol. 294, no. 2, pp. 343-348, 2006.

[15] Z. Miao, D. Xu, J. Ouyang, G. Guo, X. Zhao, and Y. Tang, "Electrochemically induced sol-gel preparation of singlecrystalline $\mathrm{TiO}_{2}$ nanowires," Nano Letters, vol. 2, no. 7, pp. 717-720, 2002.

[16] C. R. Martin, "Template synthesis of Electronically Conductive Polymer nanostructures," Accounts of Chemical Research, vol. 9, pp. 61-68, 1995.

[17] R. C. Furneaux, W. R. Rigby, and A. P. Davidson, "The formation of controlled-porosity membranes from anodically oxidized aluminium," Nature, vol. 337, no. 6203, pp. 147-149, 1989.

[18] A. Jagminas, D. Bigelienè, I. Mikulskas, and R. Tomašiūnas, "Growth peculiarities of aluminum anodic oxide at high voltages in diluted phosphoric acid," Journal of Crystal Growth, vol. 233, no. 3, pp. 591-598, 2001.

[19] M. J. Zheng, L. D. Zhang, G. H. Li, and W. Z. Shen, "Fabrication and optical properties of large-scale uniform zinc oxide nanowire arrays by one-step electrochemical deposition technique," Chemical Physics Letters, vol. 363, no. 1-2, pp. 123$128,2002$.

[20] C. Brändli, T. F. Jaramillo, A. Ivanovskaya, and E. W. McFarland, "Automated synthesis and characterization of diverse libraries of macroporous alumina," Electrochimica Acta, vol. 47, no. 4, pp. 553-557, 2001.

[21] A. Mozalev, S. Magaino, and H. Imai, "The formation of nanoporous membranes from anodically oxidized aluminium and their application to Li rechargeable batteries," Electrochimica Acta, vol. 46, no. 18, pp. 2825-2834, 2001.

[22] P. P. Mardilovich, A. N. Govyadinov, N. I. Mukhurov, A. M. Rzhevskii, and R. Paterson, "New and modified anodic alumina membranes-part I: thermotreatment of anodic alumina membranes," Journal of Membrane Science, vol. 98, no. 1-2, pp. 131-142, 1995.

[23] W.-C. Yoo and J.-K. Lee, "Field-dependent growth patterns of metals electroplated in nanoporous alumina membranes," Advanced Materials, vol. 16, no. 13, pp. 1097-1101, 2004.

[24] Z. L. Xiao, C. Y. Han, U. Welp, et al., "Fabrication of alumina nanotubes and nanowires by etching porous alumina membranes," Nano Letters, vol. 2, no. 11, pp. 1293-1297, 2002.

[25] X.-Y. Sun, F.-Q. Xu, Z.-M. Li, and W.-H. Zhang, "Cyclic voltammetry for the fabrication of high dense silver nanowire arrays with the assistance of AAO template," Materials Chemistry and Physics, vol. 90, no. 1, pp. 69-72, 2005.

[26] H. Pan, H. Sun, C. Poh, Y. Feng, and J. Lin, "Single-crystal growth of metallic nanowires with preferred orientation," Nanotechnology, vol. 16, no. 9, pp. 1559-1564, 2005.

[27] D. G. W. Goad and M. Moskovits, "Colloidal metal in aluminum-oxide," Journal of Applied Physics, vol. 49, no. 5, pp. 2929-2934, 1978.

[28] C. K. Preston and M. Moskovits, "Optical characterization of anodic aluminum oxide films containing electrochemically deposited metal particles. 1. Gold in phosphoric acid anodic aluminum oxide films," Journal of Physical Chemistry, vol. 97, no. 32, pp. 8495-8503, 1993.

[29] P. G. Sheasby and W. E. Cooke, "Electrolytic colouring of anodized aluminium," Transactions of the Institute of Metal Finishing, vol. 52, pp. 103-106, 1974.

[30] N. Zech and D. Landolt, "The influence of boric acid and sulfate ions on the hydrogen formation in $\mathrm{Ni}-\mathrm{Fe}$ plating electrolytes," Electrochimica Acta, vol. 45, no. 21, pp. 34613471, 2000.

[31] A. Jagminas, S. Lichušina, M. Kurtinaitienè, and A. Selskis, "Concentration effect of the solutions for alumina template ac filling by metal arrays," Applied Surface Science, vol. 211, no. 1-4, pp. 194-202, 2003.

[32] E. Hermann, "Elektrolytisches Färben von Anodisiertem Aluminium," Galvanotechnik, vol. 63, pp. 110-121, 1972.

[33] H. Masuda, F. Hasegwa, and S. Ono, "Self-ordering of cell arrangement of anodic porous alumina formed in sulfuric acid solution," Journal of the Electrochemical Society, vol. 144, no. 5, pp. L127-L130, 1997.

[34] A. P. Li, F. Müller, and U. Gösele, "Polycrystalline and monocrystalline pore arrays with large interpore distance in anodic alumina," Electrochemical and Solid-State Letters, vol. 3, no. 3, pp. 131-134, 2000.

[35] G. Kartopu, O. Yalçın, M. Es-Souni, and A. C. Başaran, "Magnetization behavior of ordered and high density Co nanowire arrays with varying aspect ratio," Journal of Applied Physics, vol. 103, no. 9, Article ID 093915, 6 pages, 2008. 

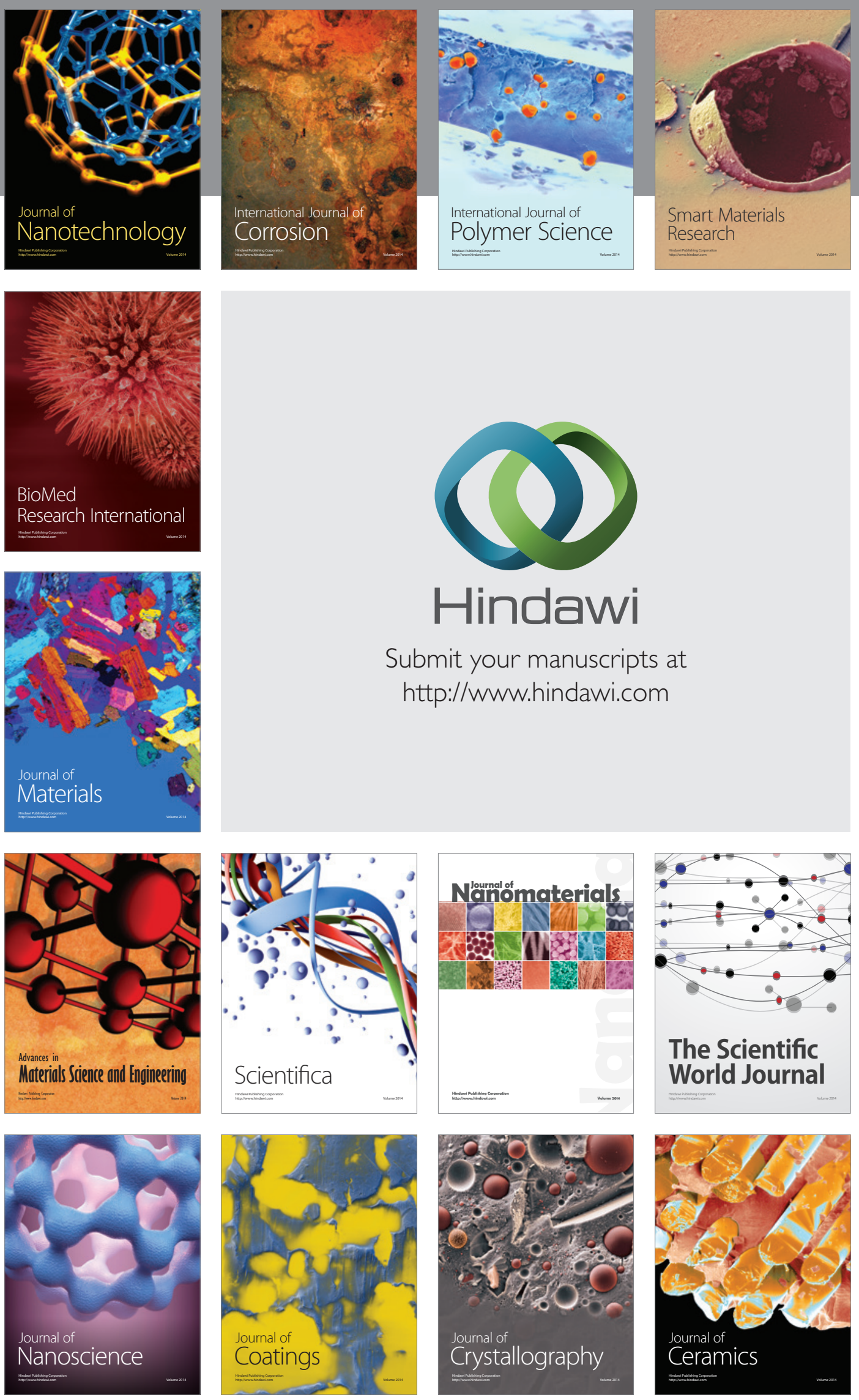

The Scientific World Journal

Submit your manuscripts at

http://www.hindawi.com

\section{World Journal}

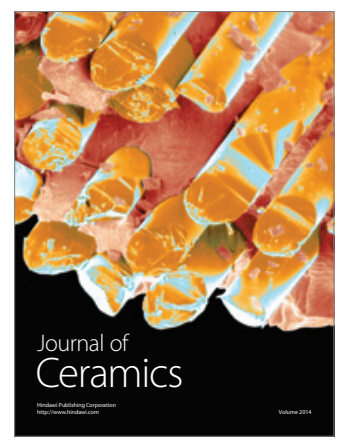

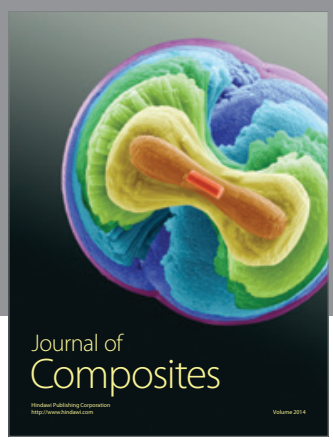
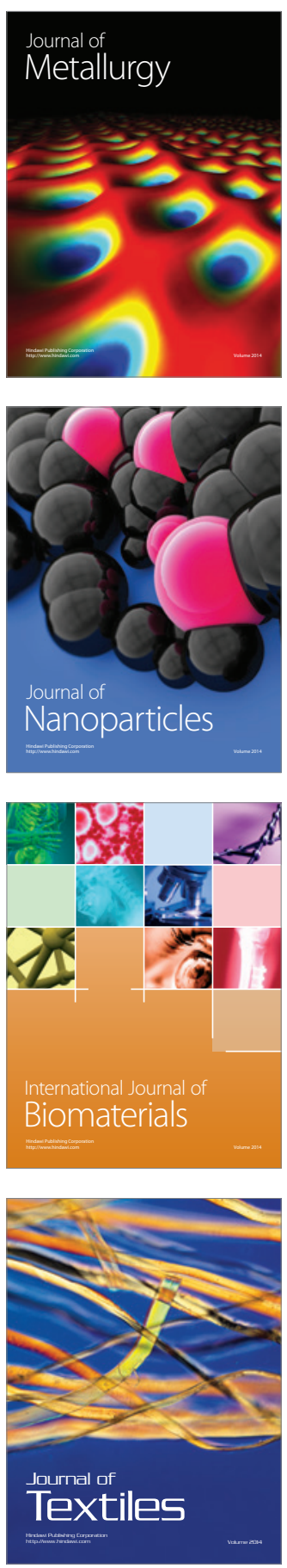